\title{
Stress at Work and Psychosomatic Complaints: A Causal Interpretation
}

\author{
Michael Frese \\ University of Pennsylvania
}

\begin{abstract}
A correlation between stress at work and psychosomatic complaints is often given a direct causal interpretation. This study examines four alternative explanations: third variables that produce spurious correlations between subjective stress and psychosomatic complaints, third variables that produce spurious correlations between objective stress and psychosomatic complaints, and the reverse causation hypothesis that psychosomatic complaints lead to more stress at work. A final set is not an actual alternative explanation but maintains that it holds only for special groups, for example those who overreport stress at work. Three studies of German, male, blue-collar workers-two cross-sectional ones $(N=206$ and $N=841)$ and one longitudinal one $(N=90)$-measured both physical and psychological stress at work on three levels: subjective response, observers' ratings, and a median rating of people doing the same work. The last two are regarded as more objective than the first. The results show that the correlation between physical stress and psychosomatic complaints can be explained by some third variable, whereas the correlation between psychological stress and psychosomatic complaints cannot be explained by any of the alternative hypotheses. Objective conditions of work stress influence the development of subjective stress and psychosomatic complaints.
\end{abstract}

Several researchers have concluded that work stress has a negative impact on the mental and physical health of workers (e.g., Cooper \& Marshall, 1976; Frese, 1978; Gardell, 1971; Gardell \& Johannson, 1981; Karasek, 1979; Kornhauser, 1965; Margolis, Kroes, \& Quinn, 1974). However, alternative explanations for the correlations between stress and ill-health variables (e.g., psychosomatic diseases) can be found.

This research is part of the research project, "Psychological Stress at Work," in which psychologists from Switzerland (U. Fellmann, I. Udris, E. Ulich, Technical University, Zurich) and from Germany (E. Bamberg, $H$. Dunckel, S. Greif, G. Mohr, D. Rueckert, M. Rummel, N. Semmer, D. Zapf, Free University, Berlin) and this author collaborated. The research was supported by a grant from the Bundesminister für Forschung und Technologie, Projektträger "Humanisierung des Arbeitslebens" to S. Greif and E. Ulich (\#01 VD 177-ZA-TAP 0016) (Greif et al., 1983) and by a grant from the Deutsche Forschungsgemeinschaft (\#FR638/1-2).

Thanks are due to E. Bamberg, R. DeRubeis, G. Mohr, P. Ovington, J. Sabini, N. Semmer, E. Skinner, I. Waldron, anonymous reviewers, and the editor for their criticism of earlier drafts of this article.

Requests for reprints may be sent to Michael Frese, Institut für Psychologie, Universität München, Organisations- und Wirtschaftspsychologie, Widenmayerstrasse 46a, D-8000 München 22, Federal Republic of Germany.
To establish the causal nature of a relationship, in addition to showing a correlation between presumed cause and effect, it is necessary to rule out alternative plausible hypotheses (Blalock, 1961). Alternative hypotheses can not be examined in most studies using only subjective measures of work stress (exception, Gardell, 1971) and not using longitudinal data (exceptions: Karasek, 1979; Karasek, Baker, Marxer, Ahlbohm, \& Theorell, 1981; Kohn \& Schooler, 1982). This article will, therefore, discuss the most important alternatives to the hypothesis that stress causes psychosomatic complaints and will determine their empirical validity.

Important alternative hypotheses can be grouped into four classes: (a) when stress at work is measured subjectively, a correlation between subjective stress and psychosomatic complaints may be spurious, that is induced by a third set of variables or method contaminations; (b) even if a correlation between objective stress and psychosomatic complaints is determined, the relationship may be explained by common effects of third variables; (c) the reverse sequence holds; and (d) the relationship between stress at work and psychosomatic complaints holds only for certain people. 
Third Variables or Method Contamination

That Could Produce the Correlation

Between Subjective Stress and

Psychosomatic Complaints

At least three of the methodological criticisms of research in this area belong to this class of alternative hypotheses. Kasl (1978) and Aldag, Barr, and Brief (1981) for example, argued that a correlation between perceived job characteristics and well-being can be explained by shared method variance (Campbell \& Fiske, 1959). Second, a response bias that results from certain people who exaggerate everything negative (or positive) about their job and their health would produce a correlation between reported stress at work and psychosomatic complaints. Third, demand characteristics of the research context (Orne, 1962) could produce a spurious correlation as well.

A somewhat different claim is the misattribution hypothesis (Jones et al., 1972). Although it has not been applied to the study of stress at work, the theory would suggest that people who have many psychosomatic complaints look for potential causes; stress at work will be a particularly popular notion, and therefore these subjects will "see" more stress at work, thus producing a spurious correlation between stress and psychosomatic complaints.

One of the best ways to rule out these hypotheses is to use objective indicators of work stress. The term objective in this context means that stressors are measured irrespective of an individual's perceptions and abilities to cope with them. If objective measures correlate with psychosomatic complaints, the relationship cannot be due to common method variance or response tendencies. For example, a correlation between perceived stress and ill health would not be replicated with objectively measured stressors if the correlation were due to response biases exaggerating stress and illhealth scores. There are, however, other third variables that could explain such correlations.

Third Variables That Could Produce the Correlation Between Objective

Indicators of Stress at Work and Psychosomatic Complaints

Five different classes of third variables could generate a spurious relationship be- tween objective stress at work and ill health. Three of them posit that a stressful job is usually only one aspect of a stressful life situation and that the other stressors (not just stress at work) may produce psychosomatic complaints. One example is job insecurity (Fein, 1976), which in lower status jobs may be associated with both more stress at work and higher psychosomatic complaints. If so, it is job insecurity, not stress at work, that produces the correlation. Another third variable is subjects' financial situation (Aldag et al., 1981; Fein, 1976): Low-paid workers often have the most stressful jobs; at the same time, financial troubles may, in and of themselves, be stressful enough to produce psychosomatic complaints. Thus, the correlation between objective work stress and psychosomatic complaints would be spurious because people stressed for other reasons tend to have objective stress at work. A third account argues that life for people of lower socioeconomic status is conducive to stress outside work (Zaleznick, Ondrack, \& Silver, 1970). This life is characterized by grim environmental circumstances (e.g., dense housing) and by a subculture that produces many problems (e.g., higher stress level at home, inadequate relationships with friends and spouse, little ego control and, therefore, more drinking and smoking). The same group of unskilled workers is also exposed to the most stressful work environments, but it is not the work environment that produces ill health; rather, it is the stressors outside work. The general assumption of these alternative hypotheses is, of course, that "lower level jobs" are more stressful than higher level jobs. This assumption is not unreasonable (cf. Karasek, 1979; Kohn \& Schooler, 1982).

One could also argue that age might be responsible for a spurious correlation and that biological age produces ill health. This view assumes that older people get more stressful jobs-an assumption that may not be true.

A final third-variables hypothesis is more complicated: People who have the most stressful jobs are most likely to want work changes that reduce stress. They may think the published relationship of work stress and psychosomatic complaints can be used to facilitate such changes. Therefore, they may exaggerate their psychosomatic complaints, 
producing a spurious correlation. One cannot check this argument directly, because the argument is based on the assumption that self-reports are invalid. An indirect indication of this tendency can be based on the assumption that people who use this strategy have generally a higher commitment than other people to change. They may, therefore, be active in the labor union (active participants in the labor union are confronted with issues of altering jobs by influencing opinions), and they probably have more clearly elaborated thoughts and suggestions about changes at the work place. For lack of a better term, this kind of third-variable hypothesis will be called political exaggeration. Variables that allow to control for the spurious effects of political exaggeration are activity in the labor union, labor union membership, and having thought about job alterations to reduce stress at work. Whatever the suspected source, the general procedure to control for spurious correlations is to partial out the relevant potential third variables (Simon, 1954).

\section{Reverse Causation Hypothesis}

This hypothesis implies that psychosomatic complaints influence the amount of objective stress in one's work situation in some subtle ways. Perhaps, persons with higher psychosomatic complaints may be less assertive and may, therefore, get the more stressful work assignments (e.g., get a machine that breaks down more often or that is older and not so easily used). These persons might be less practical in dealing with problems at their work place and, therefore, have more problems and more stress at work. This hypothesis has some similarity to the drift hypothesis originally advanced in schizophrenia research (cf. Kohn, 1973). People with psychosomatic complaints might drift downwards in the social and occupational ladder because of self- and company selection (Kasl, 1978). This drift does not necessarily occur via a succession of job changes but may come about because people with psychosomatic complaints get undesirable and stressful work places within a given job category and company. The validity of the reverse causation hypothesis can most clearly be determined by longitudinal studies.
The Causal Account Is True Only for Special Groups of People

This hypotheses is not strictly an alternative, but it does reduce the scope for which the causal relationship should be valid. Many different potential groups could be identified. The line of argument tested here is that the causal hypothesis applies differentially to people who overrate stress in comparison to workers who underrate their stress. Overraters and underraters can be determined by comparing self-reported stress to that of the colleagues and of trained observers.

Theoretically, the relationship between $o b$ jective stress at work and psychosomatic complaints may take three particularly interesting different forms for overraters and underraters; they are presented in Figure 1 (only relationships between objective stress and psychoso-
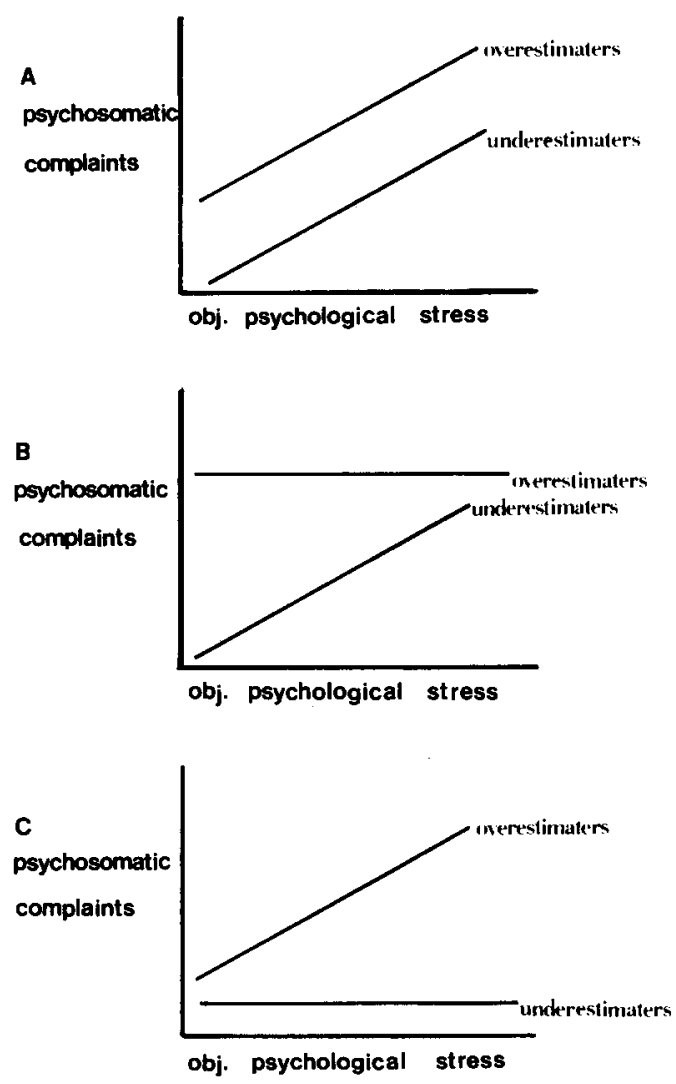

Figure 1. Possible differences between overraters and underraters with regard to the relation of objective stress to psychosomatic complaints. 
matic complaints are shown; there would be different relationships for subjective stress): (a) Objective stress at work influences the development of psychosomatic complaints in the same way for overraters and underraters, but overraters have higher psychosomatic complaints. In this case, both groups would show the same correlation (slope), but overestimaters would have an overall elevated level of psychosomatic complaints at each level of objective stress (see Figure 1A). (b) Overraters give exaggerated accounts of stress at work and of psychosomatic complaints without regard to the stressors as seen by colleagues and observers. The relationship between objective stress and their account of psychosomatic complaints would then be zero, and a nonzero correlation would only hold for underraters (see Figure 1B). (c) Only overraters are sensitive enough to stress to show the correlation between objective stress and psychosomatic complaints. In this case, only overraters would show a nonzero correlation (see Figure $1 \mathrm{C}$ ).

\section{Examination of Alternative Causal Explanations}

To investigate the alternative hypotheses described above, three studies that met certain design requirements were performed. First, it was necessary to develop measures of "objective" stress conditions. Objective is used here in the sense that the subject does not determine the measurement of stress (another meaning is possible as well, for example, a worker with less physical strength is "objectively" more stressed in a job where heavy material has to be lifted than one who is stronger-but this is not meant by the term objective as used here). Two such objective measures were employed here: observers' ratings and colleagues' ratings. Second, the alternative third variables (such as stress outside work) had to be directly measured. Third, at least one of the hypotheses (the reverse causation hypothesis) requires the use of a longitudinal study. Hence, one longitudinal study was analyzed. Finally, because the discussion has centered on relatively complicated relationships among variables (including moderator effects), it was decided to cross-validate these relationships using two cross-sectional studies.

\section{Method}

\section{Subjects}

This article is based on three studies with partly overlapping samples. In Study 1 , the sample consists of 206 workers from five different companies. Study 2 is based on 841 workers from nine different steel and automobile related companies (four of those had been included in the first study as well). Study 3 consists of 90 of the participants of Study 1 who were reinterviewed and their work places observed again 16 months later at the time of Study 2.

Overall sample characteristics. All of the subjects are German male blue-collar workers who had worked at least 6 months at their respective work places in the metal industry of the Federal Republic of Germany. The participating factories are located in rural as well as urban areas in different parts of south and middle Federal Republic of Germany. We included a wide range of bluecollar jobs. The sample ranged from physically extremely heavy jobs at the blast furnace to physically undemanding jobs in a control room (e.g., controlling the process of converting iron to steel); from simple repetitive tasks on an assembly line to highly complex tasks of a repairman of computer driven machines; and from very intensive jobs demanding fast work and quick reactions to somewhat more leisurely jobs in depots.

Subject recruitment. The subjects for the cross-sectional Studies 1 and 2 were selected with different procedures. In Study 1 the work places were selected with a brief screening instrument; this was done to obtain a wide range in the factors of control at work, complexity of work, and intensity of work speed. Our team walked through the factories and rated potential work places on these dimensions with the help of supervisors and shop stewards. Once a job was included on the basis of the screening instrument, three or more workers who where doing roughly the same work, for example, working with the same machine, producing the same product, were selected at random (except where there were fewer than four workers working in a particular job). Some of these three or more workers worked together in one group, some on different shifts. Of the $\mathbf{2 5 0}$ workers thus selected, 218 were able to participate. This difference is not due to refusals but to some organizational problems that were too difficult to overcome (e.g., some workers could not be absent from work; some workers could not miss the only bus that went to their home town and could therefore not participate if the interview was after work). Of the 218,12 more had to be rejected because the subjects were recent immigrants of German extraction from Poland; here we were not sure that they could speak German well enough.

In Study 2, subjects were selected by multiple random drawings. In the first step, names of blue-collar workers were drawn from the company pay register. Once a worker got into this random sample, three or more persons who were doing the same kind of work were randomly selected. In all, 841 workers were interviewed, and 407 work places were observed.

For Study 3, in four of the five factories of the first study a second wave of data collection occurred; one factory had substantially reduced its number of employees and was therefore not included. The return rate was 
smaller this time, because of turnover, absenteeism, vacations, and shift work schedules. Several organizational problems reduced the response rate; for example, some people could not stay after working hours to fill out the questionnnaire because of car pools. In one factory, a shortened labor week had been introduced, and people had been laid off because of the general steel crisis. Furthermore, we could not respond very flexibly because of time constraints (i.e., the need to complete the interviews in a certain number of days in each factory). The requesitioning rate ranged from $35 \%$ (in the steel factory) to $66 \%$ (in one of the automobile factories). In all, $50 \%$ $(N=90)$ were reinterviewed. The jobs of 83 participants were also reobserved.

To determine whether the sample that participated in this longitudinal study was different from the original sample, multiple $t$ tests were performed on all of the variables (35) considered to be important at Time 1 of the study. Because the purpose was to test for similarity of the samples and because the variables are correlated, multiple $t$ tests produce a conservative result. Of the 35 $t$ tests, 7 were significant $(p<.05)$. All of the differences except one were not high (criterion: higher than $1 / 2$ of the standard deviation). This is a ratio of $20 \%$, which although higher than an "expected" $5 \%$, indicates that the subjects of both waves are basically similar to the subjects who only participated in Study 1. The workers who participated in both studies had somewhat better working conditions (more variability and complexity, less organizational, social, and environmental stress, and more chances to communicate) than those not interviewed the second time.

Procedure. In all three studies, the questionnaires were filled out in groups of four to eight people in rooms provided by the companies. Interviewers explained the questionnaires, answered questions, and supervised the timing. During the sessions (which took place before, during, or after work) rest periods were provided and strict time limits were observed. The research project paid the subjects for their participation (at a pay rate higher than their usual hourly wage). In Study 1 a longer questionnaire was used; to reduce fatigue, different parts of the questionnaire were given, in permuted order, on two separate days. Because time periods for parts of the questionnaire were strictly observed, some subjects did not finish certain parts. This contributed to missing data for most of the analyses.

\section{Measures}

In general, measures used in this study were (a) first developed after interviews with open-ended, exploratory questions and then (b) tested in two to four pilot studies to ascertain that the items were understandable and that the scales were reliable (a description of the development of all the measures in this research project, the item characteristics, and the stability of the internal consistency across different subgroups can be found in Zapf et al., 1983). The scales, Cronbach's Alpha, and sample items are presented in Table 1. This table also identifies the cross-sectional study in which each variable was measured.

Stress measures. There were two measures of stress at work-psychological and physical. Each was measured in three ways: (a) subjective estimate by the subject; (b) observer's estimate; and (c) group estimate. For the observer's estimate the workers' jobs were observed for $1 \frac{1}{2} \mathrm{hr}$ by trained observers (engineers or former bluecollar workers). (More information on the measures, on the observations, and on the interrater reliabilities are given in Semmer, 1982, and Semmer, 1984.) For the group estimate, the median of each dimension could be calculated for each job, because in many cases three or more persons doing the same job (but not necessarily working together in the same group) filled out the questionnaire. This value was ascribed as a group estimate of the respective job dimension for each person. Hence, idiosyncratic and possibly illusory answers were minimized in this index. Therefore, it can be taken as a more nearly "objective" measure than the individual's estimate of the respective dimension; moreover, this index avoids the problems of the observer's brief period of observation. Because there were some jobs with fewer than three workers, the number of subjects for whom we have group measures is smaller than the number of subjects for whom we have individual subjective estimates of their working conditions $(N=668)$. (Because the group medians were calculated from the scales, no Alpha is computed at this group level.)

Psychological stress at work is a composite index of scales concerning uncertainty in the job (such as ambiguities and conflicts), organizational problems (e.g., not getting material) environmental stress (e.g., noise), danger of accidents, and intensity (i.e., speed of work). The different scales of this index are related to each other; hence one can form a new scale with the above scales as items (in the first study the alpha was .73 for the subjective level with five scales as items, .76 for the group level with five scales as items, and .52 for the observed level with four scales as items; the respective alphas in Study 2: .76, .79, .65). The index of physical stress is composed of two indexes, one on one-sided stress of parts of the body and another one on physical intensity of work. (The correlations between these two indexes are $r=.27, N=189, p<.001 ; r=.25, N=175, p<.001$; and $r=.39, N=195, p<.001$ for the subjective, group, and observed levels, respectively, in Study 1 and $r=.32$, $N=760, p<.001 ; r=.41, N=681, p<.001$; and $r=.49, N=383, p<.001$, for the three levels in Study 2). The interrelations of the stress scales are given in Table 2.

Psychosomatic complaints. The psychosomatic complaint list was a slightly modified version of the scale by Fahrenberg (1975; modified by Mohr, 1985). It lists several psychosomatic complaints, such as headaches, stomach aches, and so forth, and is similar to various English scales of somatic complaints (e.g., the one used by Caplan, Cobb, French, Harrison, \& Pinneau, 1975). This variable correlates meaningfully with other variables related to medical problems $(r=.27, N=824, p<$ .001 , with seeing a physician; $r=.63, N=772, p<$ .001 , with the use of medications). In the longitudinal study, two parallel forms of this scale were used.

Indicators of third variables. As potential third variables, the following scales were developed and measured only on the subjective level: As an approximate measure of job insecurity Alternatives on the labor market asks whether the subject perceives himself able to get another job any time he wants to; thus, it ascertains whether one 
would stay unemployed if one were to become unemployed. This scale correlates $r=-.66(N=179, p<$ .001 ) with job insecurity (that was developed by Semmer, 1984) in Study 1. Leisure time stress (developed by Bamberg, 1985) includes social and personal problems such as inability to pursue one's hobbies (sample items "everybody wants something different from $\mathrm{me}^{\mathrm{e}}$-in the sense that there are conflicting demands, "I do not have enough time," "I meet people I do not like"). The scale on lack of support by wife (developed by Bamberg, 1985)

Table 1

Main Measures: Their Item Content and Reliabilities

Reliabilities (alphas)

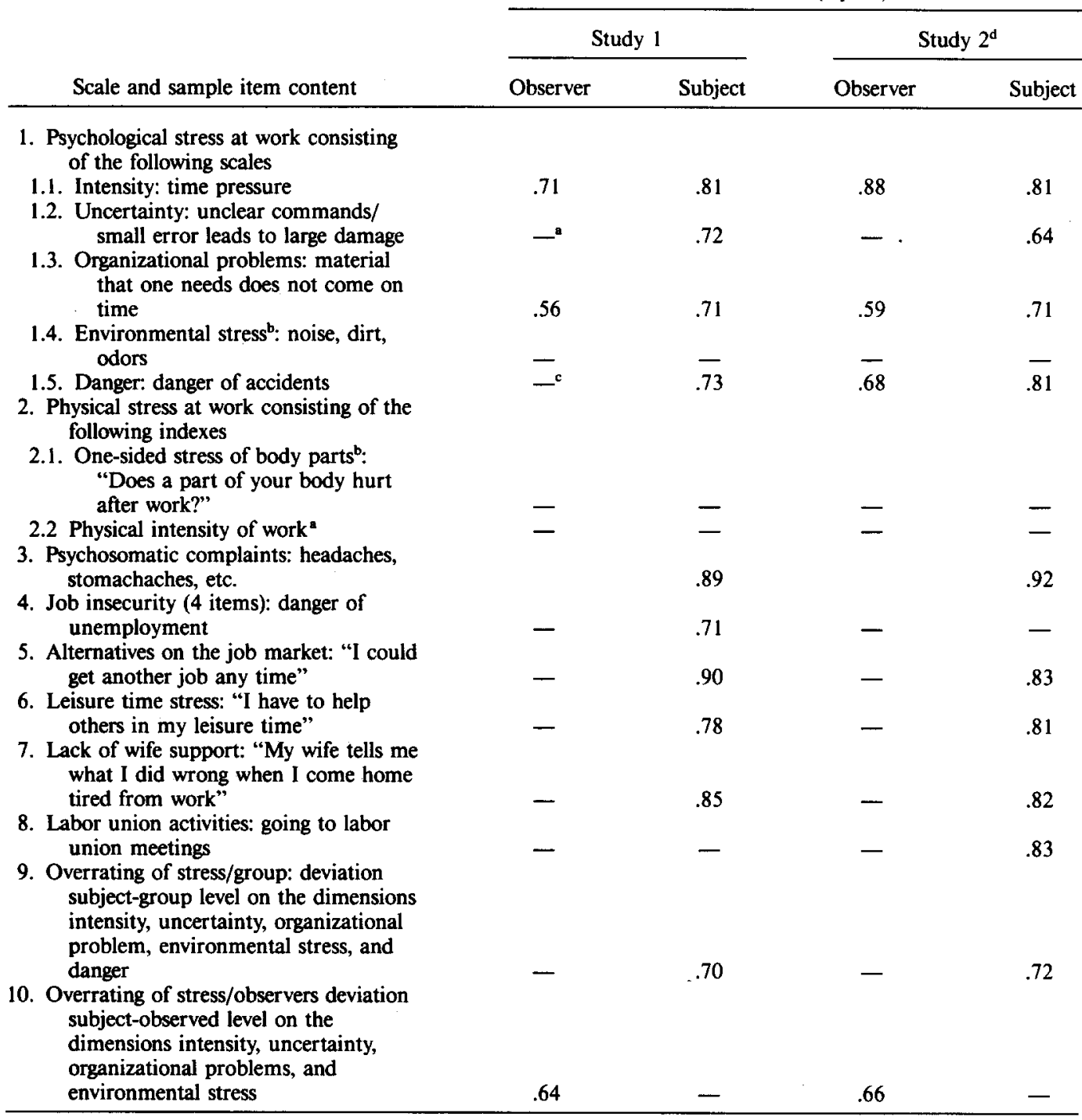

: Only one item in the observed version of this scale; therefore, no reliability computed.

${ }^{b}$ No reliability was computed for this index because there is no theoretical reason that the different items should correlate highly.

c This scale was only used in the subjective version. Therefore, the subjective and group versions of the index psychological stress include one more scale than the observed.

deliabilities are based on $N=841$ of the second study plus $N=90$ persons of the longitudinal study ( $N=931$ for subjective indices; $N=490$ for the observed indices). 


\begin{tabular}{|c|c|c|c|c|c|c|}
\hline $\begin{array}{c}\text { Types of stress } \\
\text { and level }\end{array}$ & 1 & 2 & 3 & 4 & 5 & 6 \\
\hline \multicolumn{7}{|l|}{$\begin{array}{l}\text { Psychological } \\
\text { I Subjective }\end{array}$} \\
\hline $\begin{array}{c}r \\
N \\
2 \text { Group }\end{array}$ & & $\begin{array}{l}.63^{* *} \\
(172)\end{array}$ & $\begin{array}{l}.34^{* *} \\
(173)\end{array}$ & $\begin{array}{l}.41^{* * *} \\
(162)\end{array}$ & $\begin{array}{l}.17^{*} \\
(151)\end{array}$ & $\begin{array}{l}-.01 \\
(166)\end{array}$ \\
\hline $\begin{array}{l}r \\
N \\
3 \text { Observed }\end{array}$ & $\begin{array}{l}.61^{* *} \\
(668)\end{array}$ & & $\begin{array}{l}.49^{* *} \\
(159)\end{array}$ & $\begin{array}{l}.15^{*} \\
(161)\end{array}$ & $\begin{array}{l}.15^{*} \\
(172)\end{array}$ & $\begin{array}{l}-.16^{*} \\
(174)\end{array}$ \\
\hline $\begin{array}{c}r \\
N \\
\text { Physical } \\
\text { 4 Subjective }\end{array}$ & $\begin{array}{l}.37^{* *} \\
(385)\end{array}$ & $\begin{array}{l}.42^{* *} \\
(286)\end{array}$ & & $\begin{array}{l}-.05 \\
(162)\end{array}$ & $\begin{array}{l}-.10 \\
(157)\end{array}$ & $\begin{array}{c}-.22 * * \\
(177)\end{array}$ \\
\hline $\begin{array}{l}r \\
{ }^{N} \text { Group }\end{array}$ & $\begin{array}{l}.39^{* *} \\
(748)\end{array}$ & $\begin{array}{l}.22^{* *} \\
(619)\end{array}$ & $\begin{array}{l}.12^{* *} \\
(359)\end{array}$ & & $\begin{array}{l}.62^{* *} \\
(163)\end{array}$ & $\begin{array}{l}.39^{* *} \\
(180)\end{array}$ \\
\hline $\begin{array}{l}r \\
N \\
6 \text { Observed }\end{array}$ & $\begin{array}{l}.21^{* *} \\
(668)\end{array}$ & $\begin{array}{l}.42^{* *} \\
(681)\end{array}$ & $\begin{array}{l}.15^{* *} \\
(286)\end{array}$ & $\begin{array}{l}.44^{* * *} \\
(619)\end{array}$ & & $\begin{array}{l}.51^{* *} \\
(173)\end{array}$ \\
\hline $\begin{array}{l}r \\
N \\
\end{array}$ & $\begin{array}{l}.12 * * \\
(379) \\
\end{array}$ & $\begin{array}{l}.14^{* *} \\
(284) \\
\end{array}$ & $\begin{array}{l}.17^{* *} \\
(378) \\
\end{array}$ & $\begin{array}{l}.33^{* *} \\
(375) \\
\end{array}$ & $\begin{array}{l}.30^{* * *} \\
(284)\end{array}$ & \\
\hline
\end{tabular}

Note. Upper diagonal: Study 1 and lower diagonal: Study 2.

${ }^{*} p<.05{ }^{* *} p<.01$.

includes items on how much understanding the wife shows (e.g., "My wife tells me to do certain chores when I come home tired from work." "She tells me what I do wrong when I come home tired from work." "I am not able to tell her my problems when I come home tired from work.") Whenever this scale is used in an analysis, the number of subjects is reduced considerably because only married subjects are included.

Political exaggeration was indexed with three measures: First, a scale on labor union activities is concerned with how much an individual participates in the labor union. Second, for the analysis of how much people have thought about changes in the work place that would reduce stress, a sort of creativity format was used. In an open-ended question, the subject was asked to state as many methods to reduce stress at work as he could think of. "Suggestions for job changes" was quantified by the number of suggestions given without evaluating the suggestions in terms of content (on average 2.3 methods were suggested, $s=$ 2.1). Third, single items ask whether one has an office in the labor union and if one is a member of the labor union.

Additional single items that are potentially related to life in lower socioeconomic status (SES) groups refer to skill level (a dichotomous item on having been an apprentice), square meters of housing (for density), number of cigarettes smoked per day, number of bottles of beer drunk, and, finally an item which asks whether the subject has grown up in a small town (fewer than 10,000 inhabitants) or in a city. A question on education was not included in the analyses because with only a few exceptions, the subjects had gone to primary school only $(96 \%)$.
Finally, overrating and underrating of stress at work was measured with deviations scores: subjective level of stress minus group level. To do this, the stress dimensions were $z$ standardized and each group-level stressor was subtracted from the subjective-level stressor. The resulting deviation scores for each person can be combined into one scale "overrating of stress/group" with adequate reliabilities (cf. Table 1). The same type of scale was developed for the deviation of subjective from observed stress at work, "overrating of stress/observers." These two scales correlate substantially with each other $(r=$ $.52, p<.001$ in each of the two studies).

\section{Results and Discussion}

Each of the four groups of alternative hypotheses will now be evaluated step by step.

Third variables or method contamination that produce the correlation between subjective stress and psychosomatic complaints. A correlation between objective indicators of work stress and psychosomatic complaints tests whether the correlation between subjective stress and psychosomatic complaints is due to demand characteristics, exaggeration, or misattribution. Two indicators that are more objective than subjective estimates are observational ratings and group estimates. 
Table 3

Correlations Between Measures of Subjective and Objective Stress and Psychosomatic Complaints

\begin{tabular}{llllll}
\hline \multirow{2}{*}{$\begin{array}{c}\text { Type of } \\
\text { stress and } \\
\text { level }\end{array}$} & \multicolumn{2}{c}{ Study 1 } & & \multicolumn{2}{c}{ Study 2} \\
\cline { 2 - 3 } \cline { 5 - 6 } & $r$ & $N$ & & $r$ & $N$ \\
\hline $\begin{array}{llllll}\text { Psychological } \\
\text { Subjective }\end{array}$ & $.40^{* *}$ & 172 & & $.31^{* *}$ & 816 \\
$\quad$ Group & $.23^{* *}$ & 173 & & $.16^{* *}$ & 675 \\
$\quad \begin{array}{l}\text { Observed } \\
\text { Physical }\end{array}$ & $.18^{* *}$ & 175 & & $.19^{* *}$ & 384 \\
$\quad$ Subjective & $.38^{* *}$ & 190 & & $.39^{* *}$ & 653 \\
Group & $.27^{* *}$ & 172 & $.07^{*}$ & 592 \\
Observed & .02 & 193 & .07 & 280 \\
\hline
\end{tabular}

$* p<.05{ }^{* *} p<.01$.

The correlations of subjective, group, and observer ratings of psychological and physical stress with psychosomatic complaints for Studies 1 and 2 are presented in Table 3 . The correlations between subjective psychological stress and psychosomatic complaints in both studies were relatively sizable (between .30 and .40). Although the correlations with the "objective" indicators of work stress (around .20) are lower, they were significant and similar across the two studies. For ratings of physical stress, however, the sizable and similar correlations between the subjective index and psychosomatic complaints disappear when the group and the observer estimates are used. Thus, a third variable might explain the relation between subjective physical stress and psychosomatic complaints. Our design does not allow one to say what is responsible for this. It is plausible that workers would, in fact, search for more external physical causes when they have physical (psychosomatic) symptoms. However, it is also possible that the observational measure of physical stress was not sufficiently developed.

The correlations between "objective" psychological stress and psychosomatic complaints do not seem to be very high. On the other hand, the two objective indexes contribute to a relatively conservative estimate of the correlation. As with all other procedures, these indicators have certain drawbacks. Observers are not able to observe in $1 \frac{1 / 2}{2}$ hours all the potential stressors at the work place. Moreover, the peak periods of stress are unlikely to be observed at all. Also, there seems to be a stronger halo effect in the observers' ratings than in the ratings by the jobholders (Semmer, 1984).

For these reasons, the group index might be more valid than the observers' ratings. The jobholders have, of course, observed their work places much more extensively than anyone else. Thus, they are "experts" on their jobs. On the other hand, there is the danger that their individual characteristics (e.g., their level of ill health, their coping skills, their abilities, and idiosyncracies) influence their perception of stressors. The grouplevel judgment tends to minimize idiosyncratic perceptions. However, this measure also presents some problems because no two work places are actually identical. Even when the same machines are used, one machine may be nearer to a source of loud noise, it may break down more often, or it may be more closely supervised because it can be more conveniently observed by the foreman. Moreover, people doing the same work are usually not using exactly identical machines but only similar ones. These factors could contribute to noise in the data that would weaken the correlations. Therefore, the correlations of these two "objective" indicators with psychosomatic complaints are probably conservative and represent the lower bound of the "true" relationship between objective indicators of work stress and psychosomatic complaints.

In summary, in the case of psychological stress, the size of the correlation shrinks somewhat with the use of more objective indicators. However, the correlations show a remarkable stability across the two studies. Because these correlations of about .20 must be interpreted as the lower bound, these results are important enough to warrant testing the other alternative hypotheses. Physical stress does not show stable correlations with psychosomatic complaints and will therefore not be considered further in the following analyses.

Third variables that produce the correlation between objective stress and psychosomatic complaints. Five sets of third variables were examined using the data from Studies 1 and 2: financial situation, job insecurity (alternatives on the job market), life of low SES groups, age, and political exaggeration. These potential third variables were partialed out 
of the correlation between the two "objective" indicators of psychological stress at work and psychosomatic complaints. In Table 4 the partial correlations are presented with the zero-order correlations given in the bottom row for comparison. (These zero-order correlations actually fluctuated a little across the analyses, as the number of subjects changes

Table 4

Correlations Between Objective Psychological Stress and Psychosomatic Complaints

With the Effects of Alternative Hypotheses Partialed out

\begin{tabular}{|c|c|c|c|c|}
\hline \multirow[b]{3}{*}{ Variable(s) to be partialed out } & \multicolumn{4}{|c|}{ Partial correlations } \\
\hline & \multicolumn{2}{|c|}{ Study 1} & \multicolumn{2}{|c|}{ Study 2} \\
\hline & $\begin{array}{l}\text { Group } \\
\text { level }\end{array}$ & $\begin{array}{l}\text { Observed } \\
\text { level }\end{array}$ & $\begin{array}{l}\text { Group } \\
\text { level }\end{array}$ & $\begin{array}{l}\text { Observed } \\
\text { level }\end{array}$ \\
\hline \multicolumn{5}{|l|}{$\begin{array}{l}\text { 1. Financial situation (income of } \\
\text { family after taxes) }\end{array}$} \\
\hline $\begin{array}{l}r \\
\text { 2. Job insecurity }\end{array}$ & $\begin{array}{l}.26^{* *} \\
(162) \\
.20^{* *} \\
(162)\end{array}$ & $\begin{array}{l}.18^{*} \\
(162) \\
.13^{*} \\
(162)\end{array}$ & $\begin{array}{c}.17^{* *} \\
(638) \\
.17^{* *} \\
(638)\end{array}$ & $\begin{array}{l}.18^{* *} \\
(366) \\
.18^{* *} \\
(366)\end{array}$ \\
\hline \multicolumn{5}{|l|}{$\begin{array}{l}\text { 3. Life of low socioeconomic } \\
\text { status groups }(a-h)\end{array}$} \\
\hline $\begin{array}{l}\text { a. Grown up in town/city } \\
\text { (dichotomous) }\end{array}$ & $\begin{array}{l}.24^{* *} \\
(136) \\
.21^{* *}\end{array}$ & $\begin{array}{l}.19^{*} \\
(137) \\
.20^{* *}\end{array}$ & $\begin{array}{l}.18^{* *} \\
(490) \\
.15^{* *}\end{array}$ & $\begin{array}{l}.17^{* *} \\
(280) \\
.17^{* *}\end{array}$ \\
\hline b. Leisure time stress & $(136)$ & (137) & $(490)$ & $(280)$ \\
\hline c. Wife not supporting & $\begin{array}{l}.24^{* *} \\
(136)\end{array}$ & $\begin{array}{l}.17^{*} \\
(137)\end{array}$ & $\begin{array}{l}.20^{* *} \\
(490)\end{array}$ & $.21^{* *}$ \\
\hline d. Skill level ${ }^{\mathrm{a}}$ & _ & - & $\begin{array}{l}.18^{* * *} \\
(490)\end{array}$ & $.20^{* *}$ \\
\hline e. $\mathrm{m}^{2}$ of housing & $\begin{array}{l}.25^{* *} \\
(136)\end{array}$ & $\begin{array}{l}.20^{* *} \\
(137)\end{array}$ & $\begin{array}{l}.18^{* *} \\
(490)\end{array}$ & $\begin{array}{l}.19^{* *} \\
(280)\end{array}$ \\
\hline f. Use of a garden & $\begin{array}{l}.22^{* *} \\
(136)\end{array}$ & $\begin{array}{l}.18^{*} \\
(137)\end{array}$ & $\begin{array}{l}.18^{* *} \\
(490)\end{array}$ & $\begin{array}{l}.18^{* *} \\
(280)\end{array}$ \\
\hline g. No. of cigarettes" & - & - & $\begin{array}{l}18^{* *} \\
(490)\end{array}$ & $\begin{array}{l}.19^{* *} \\
(280)\end{array}$ \\
\hline h. No. of bottles of beer & - & $一^{a}$ & $\begin{array}{l}.17^{* *} \\
(490)\end{array}$ & $\begin{array}{l}.18^{* *} \\
(280)\end{array}$ \\
\hline a to $h$ together & $\begin{array}{l}.18^{*} \\
(132)\end{array}$ & $\begin{array}{l}.15^{*} \\
(133)\end{array}$ & $\begin{array}{c}14^{* *} \\
(483)\end{array}$ & $\begin{array}{l}.17^{* * *} \\
(273)\end{array}$ \\
\hline 4. Age & $\begin{array}{l}.19^{* *} \\
(163)\end{array}$ & $\begin{array}{l}.13^{*} \\
(174)\end{array}$ & $\begin{array}{l}.15^{* *} \\
(669)\end{array}$ & $.18^{* *}$ \\
\hline 5. Political Exaggeration $(a-c)$ & & & & \\
\hline a. Suggestions for job changes & - & - & $\begin{array}{l}.17^{* *} \\
(643)\end{array}$ & $\begin{array}{l}.16^{* *} \\
(363)\end{array}$ \\
\hline $\begin{array}{l}\text { b. No of offices in labor } \\
\text { union" }\end{array}$ & - & - & $-.17^{* *}$ & $\begin{array}{l}.16^{* *} \\
(363)\end{array}$ \\
\hline c. Labor union activities" & - & - & $\begin{array}{l}.16^{* *} \\
(643)\end{array}$ & $\begin{array}{l}.17^{* *} \\
(363)\end{array}$ \\
\hline $\begin{array}{l}\text { a to } c \text { together (political } \\
\text { exaggeration) }\end{array}$ & - & - & $\left(16^{* *}\right.$ & $.15^{* *}$ \\
\hline $\begin{array}{l}\text { All of the above variables } \\
\text { together }(1-5)\end{array}$ & - & - & $\begin{array}{l}.15^{* *} \\
(440)\end{array}$ & $\begin{array}{l}.15^{* *} \\
(252)\end{array}$ \\
\hline Zero-order correlation & $\begin{array}{l}.23^{* *} \\
(172)\end{array}$ & $\begin{array}{l}.18^{* *} \\
(175)\end{array}$ & $\begin{array}{l}.16^{* *} \\
(675)\end{array}$ & $\begin{array}{l}.19^{* *} \\
(384)\end{array}$ \\
\hline
\end{tabular}

\footnotetext{
- Not used in first study.

b When this variable is included, the nonmarried men are excluded; therefore, there is a substantial drop of the $N$; however, if this variable is not included, the results do not differ from the ones shown here.

$*=p<.05$. $^{* *}=p<.01$.
} 
depending upon the analysis: There were fewer subjects in the objective conditions, the inclusion of the variable "wife not supporting" led to the exclusion of single men, and there were missing data.) The correlations remained and were only slightly reduced when income, job insecurity, the variables pertaining to life in low SES, age, and the variables of political exaggeration were partialed out. Furthermore, there was a remarkable similarity across the two cross-sectional studies. The sample size of Study 2 allowed for the inclusion of all of the 14 potential third variables in one partial correlation. The resulting partial correlations between psychosomatic complaints and the two measures of objective psychological stress were .15 ( $d f=$ $440, p<.01$ ) for group-level psychological stress and $.15(d f=252, p<.01)$ for observed psychological stress. This supports the conclusion that the hypothesized third variables have little impact on the relationship between stress and psychosomatic complaints. Possibly other third variables, not addressed in this study, could account for the correlation between objective psychological stress and psychosomatic complaints. But at least the most plausible third variables measured in our study do not explain the correlation.

Although the accuracy of most responses related to the potential third variables is probably quite good, two indexes-beer drinking and cigarette smoking - may be underreported (the mean of 8.68 bottles per week appears to be very low compared to average national consumption). Therefore, the results are still provisional with regard to alcohol and nicotine consumption.

The reverse causation hypothesis. To test this hypothesis, a cross-lagged panel correlation design with special features was used in the analysis of Study 3. First, because stabilities of the variables will affect the crosslagged correlations (Rogosa, 1980), the stabilities were partialed out (as was done by Pelz \& Andrews, 1964). Second, before the cross-lagged correlations were computed, stationarity in the data was required, meaning that the cross-sectional relationships between stress and psychosomatic complaints had to be similar at the two time periods. Finally, the variances of the variables were checked to determine whether there was an increase or decrease over time. All the requirements were met. The differences between the crosslagged partial correlations were computed with Steiger's (1980) Formula 15. Table 5 shows the cross correlations, the stabilities, and the zero-order and partial cross-lagged correlations.

The results were not completely consistent. On the subjective level and on the group level the differences between the partial cross-lagged correlations were significant. This favors the hypothesis that work stress contributes to psychosomatic complaints. The difference between the cross-lagged partial correlations on the observed level, on the other hand, were not significant. Thus, on the observed level there is no evidence for the causal priority of either set of factors.

The following interpretation seems to be adequate: The results on the observed level may be due to having used different groups of observers in the two waves (in the first wave engineers and in the second one psychology students who were particularly well trained). This might also have contributed to the relatively low stability of observed stress $(r=.41)$. Moreover, it is difficult to obtain clear-cut results in a time period of 16 months. Although there were technological changes of the jobs in this time, they were not major. It might also take longer than 16 months for changes at work to affect the development of psychosomatic complaints. Because it is difficult to obtain clear-cut results, it is all the more striking that we got statistically significant results. The results are not only significant on the subjective level but also on the "objective" level of group estimates of stress at work. All of the results contradict the reverse causation hypothesis. Thus, there is some support for the hypothesis that work stress contributes to psychosomatic complaints, although the results are not as clear-cut as one would like them to be.

The causal account is true only for $a$ special group of people. The relevant moderator variables to be considered here are overreporting or underreporting as measured by deviation scores between the individuals' subjective stress rating and objective indicators (either group or observed "objective" stress).

Three roughly equal-size groups were formed on each of the two deviation variables, 
and the respective correlations between stress at work and psychosomatic complaints were computed. The correlations between the "objective" indicators of work stress and psychosomatic complaints for underraters, middle group, and overraters are shown in Table 6. Although there are some inconsistencies in the data, the overall picture is one of remarkable similiarity of the correlations across the three different groups. The same results prevail when using moderated regression (Zedeck, 1971). The interaction term "Stress $X$ Overreporting" does not approach signifcance in any of the analyses on the subjective, group, and observed level in either crosssectional study. Stress at work seems to be operative independent of a person's tendency to overestimate or underestimate stress; therefore, the hypothesis as depicted in Figure 1 A seems to be correct.

An additional feature of the theoretical presentation of Figure $1 \mathrm{~A}$ is that the mean for psychosomatic complaints should be higher for overraters than for underraters. Here, the data were not as clear cut. In Study 1 , there were no significant differences between the means of psychosomatic complaints for underraters, middle group, and overraters. In Study 2, the differences are significant, $F(2,377)=3.2, p<.05$, for "overrating of stress/observers," and $F(2,659)=18.8, p<$ .01 , for "overrating of stress/group." Thus, there is rather strong support for the claim that the slope of the curves is similar for the three groups and some support for the hypothesis displayed in Figure 1A, that at each level of stress at work there are more psychosomatic complaints in the overraters.

\section{Overall Discussion}

Before discussing the conclusions to be drawn from the findings of this study, two general issues will be discussed: (a) the problem of the size of the correlations and (b) issues relating to self-report measures of psychosomatic complaints. The low size of the correlations between stress at work and ill health is often taken as an indication that this relationship is not important (e.g., Kasl, 1978). The correlations of this study are around .20 when using objective indicators and therefore explain $4 \%$ of the variance. Before one jumps to the conclusion, however, 


\begin{tabular}{|c|c|c|c|c|c|c|c|c|c|c|c|c|}
\hline \multirow{3}{*}{$\begin{array}{l}\text { Correlation of } \\
\text { psychosomatic } \\
\text { complaints with }\end{array}$} & \multicolumn{4}{|c|}{ Underraters } & \multicolumn{4}{|c|}{ Middle group } & \multicolumn{4}{|c|}{ Overraters } \\
\hline & \multicolumn{2}{|c|}{ Dev/observ } & \multicolumn{2}{|c|}{ Dev/group } & \multicolumn{2}{|c|}{ Dev/observ } & \multicolumn{2}{|c|}{ Dev/group } & \multicolumn{2}{|c|}{ Dev/observ } & \multicolumn{2}{|c|}{ Dev/group } \\
\hline & $r$ & $\mathbf{N}$ & $r$ & $\mathbf{N}$ & $r$ & $\mathrm{~N}$ & $r$ & $N$ & $r$ & $N$ & $r$ & $N$ \\
\hline
\end{tabular}

First study

\begin{tabular}{|c|c|c|c|c|c|c|c|c|c|c|c|}
\hline \multirow{3}{*}{$\begin{array}{l}\text { "Group" } \\
\text { psychological } \\
\text { stress } \\
\text { Observed psycholog- } \\
\text { ical stress }\end{array}$} & .12 & $(46)$ & .23 & $(48)$ & $.32^{*}$ & $(45)$ & $.29 *$ & $(52)$ & .23 & $(49)$ & $.27^{*}$ \\
\hline & & & & & & & & & & & \\
\hline & .19 & (51) & .21 & (46) & $.40^{*}$ & (49) & $.25^{*}$ & (44) & $.24^{*}$ & $(52)$ & .14 \\
\hline
\end{tabular}

"Group"

psychological

\begin{tabular}{|c|c|c|c|c|c|c|c|c|c|c|c|c|}
\hline $\begin{array}{l}\text { psyce } \\
\text { stress }\end{array}$ & $.26^{* *}$ & (89) & $.19^{* *}$ & $(214)$ & $.19^{*}$ & (91) & $.19^{*}$ & (224) & -.01 & (101) & $.21^{* *}$ & 224) \\
\hline d nsycholog- & & 23) & & 30) & 32 & 27) & .16 & 3) & & 130) & $7^{*}$ & \\
\hline
\end{tabular}

Note. Dev/observ $=$ deviation of subjective score from observers. Dev/group = deviation of subjective score from co-workers.

${ }^{*} p<.05{ }^{* *} p<.01$.

that this size of the correlation is too low for practical matters, three points must be considered: (a) from a theoretical, and (b) from a methodological point of view one would only expect small correlations; and (c) small correlations may represent substantial effects for the extremes of a population.

There are good theoretical reasons that the work situation is only one of the many influential factors that contribute to ill health (Frese, 1982). Other factors, such as stress outside work, personal habitat, biological factors, and so forth, also contribute to ill health. One would, therefore, expect only a low correlation between work stress and psychosomatic complaints.

Methodological reasons speak for low correlations as well. As already pointed out, the correlations using the "objective" indicators of work stress probably represent the lower bound of the true correlation between objective stress and psychosomatic problems. Furthermore, any research that samples subjects from a working population tends to underestimate the "true" relationship between stress at work and ill health because of restriction of variance of the dependent variable. People who have become ill due to stress at work will be absent more often, will be unemployed more frequently, or will retire sooner and thus be underrepresented in the sample (e.g., about one half to two thirds of the German blue-collar workers retire early because of disability). Thus, there is a healthy worker effect (Frese \& Okonek, 1984; McMichael, 1976; Waldron, Herold, Dunn, \& Staum, 1982). Moreover, this problem is aggravated in our study because only blue-collar workers were sampled, which presumably leads to a restriction of variance in the stressors.

In terms of substance, even a small correlation may be very important if one looks at the extremes of the sample. This can be shown in our second cross-sectional study (in the first one the small $N$ makes such an analysis less useful). Figure 2 presents the percentages of psychosomatically impaired (those with a score of 3.5 and above on a 5point scale) on each level of stress at work. As one can see, there are nine times more workers seriously impaired on the highest than on the lowest stress level (this is equivalent to a correlation of .31). Similarly a correlation of .19 between observed psychological stress at work and psychosomatic complaints translates into a ratio of 1 to 3 . 


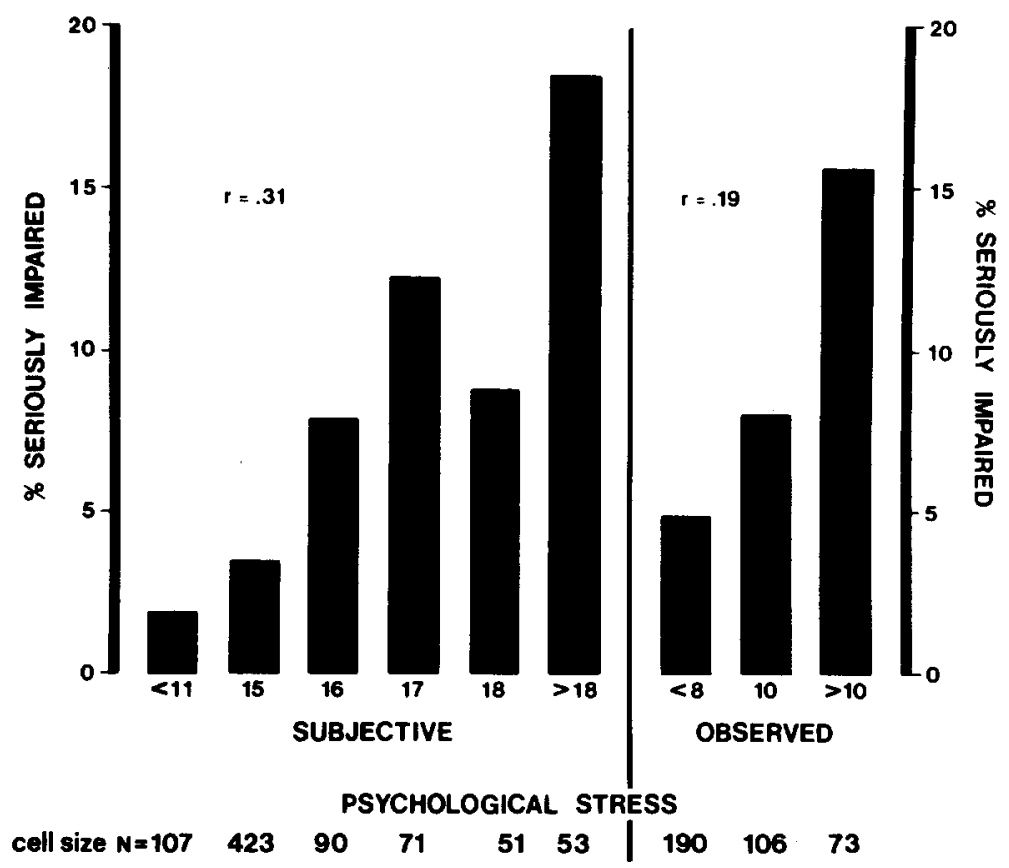

Figure 2. Percentage of serious psychosomatic impairment at each level of stress at work: A comparison of absolute effects and correlations.

These results speak for the practical importance of even small correlations.

Another problem of the kind of research reported here is the question of measuring psychosomatic problems with a questionnaire. Questionnaire measures are often met with skepticism because "complaint without substance" factors are assumed to operate. This factor does not explain the correlation between stress and psychosomatic complaints in this study, however, as shown in the analysis of overraters and underraters of stress. A related criticism is that questionnaire measures of psychosomatic problems do not measure real physical diseases, for example, as seen by a physician. Although it is not possible to refute this criticism completely, several considerations shake the plausibility of such an assertion. First, there are sizeable correlations between psychosomatic complaints and illness-related behaviors (visits to a physician and taking medicine) that are societally and individually important. Second, other studies (LaRue, Bank, Jarvik, \& Hetland, 1979, Maddox \& Douglass, 1973, Mossey \& Shapiro, 1982, Waldron et al., 1982) show that subjective health data-even much sim- pler and more general questions than the ones used in this study-are good predictors of actual mortality (sometimes better than physicians' ratings). Some of the items of our psychosomatic complaint scale were shown by Karasek et al. (1981) to predict death from coronary heart disease (items on heart ache and trouble breathing). Finally, Meltzer and Hochstim (1970) analyzed the relation between subjective health data and medical ratings and found that there is a larger number of false negatives than false positives in questionnaire answers. Questionnaire measures may therefore underestimate rather than overestimate the true health problems of the respondents.

In summary, the results have shown a difference between the effects of psychological and physical stress at work: The relationship of subjective physical stress with psychosomatic complaints did not hold up when "objective" indicators of physical stress were used. Therefore, further tests with physical stress were abandoned. The results indicate that the correlation of stress and psychosomatic complaints is not spurious and cannot easily be explained by methodological arti- 
facts; by variables such as income, job insecurity, and age; or by variables related to a stressful life of low SES groups and "political exaggeration." Furthermore, the relationship between psychological stress at work and psychosomatic complaints is not confined to overraters or underraters. Finally, most data favor the interpretation that stress is a cause of psychosomatic complaints, not the reverse. Three other longitudinal studies, although based on subjective data, corroborate the conclusions that stress at work leads to psychosomatic and physical ill health (Karasek, 1979, Karasek et al., 1981, Kohn \& Schooler, 1982). In all, four classes of alternatives to the hypothesis that "objective" work stress as measured by colleagues and observers contributes to psychosomatic complaints were not supported, strengthening the case for a direct causal link. This is in line with conclusions by Gardell (1971), whose study was based on observers' ratings of the work place and by Wall and Clegg (1981), whose study showed that interventions in the work place by introducing semiautonomous work groups led to an improvement in mental health. Similarly, Broadbent (1982), using a different line of reasoning and referring to a different set of empirical studies on the relationship between stress at work and well-being, came to very similar conclusions with regard to the causal influence of stress at work.

The results have some implications for a theory of stress effects. The influential cognitive model of stress (Lazarus, 1966) has emphasized the importance of cognitive factors such as subjective cognitions of stress (primary appraisal) and one's coping responses (based on secondary appraisal). This has led many authors to concern themselves with perceived stress rather than with the objective work environment. Consequently, when suggesting methods to reduce stress at work, some authors have emphasized relaxation training, or the teaching of adequate coping responses, rather than directly changing the work place (e.g., Cooper, 1981, Ellis, 1978). The results of this study do not directly contradict these suggestions, nor do they invalidate Lazarus's theory. But they do underline the importance of the objective work environment as a major determinant of one's subjective stress and an influence on the development of psychosomatic complaints. A new look at the importance of the objective environment seems therefore warranted.

\section{References}

Aldag, R. J., Barr, S. H., \& Brief, A. P. (1981). Measurement of perceived task characteristics. Psychological Bulletin, 90, 415-431.

Bamberg, E. (1985). Arbeit und Freizeit: Eine empirische Untersuchung zum Zusammenhang zwischen Stress am Arbeitsplatz, Freizeit und Familie. (Work and leisure time: Empirical research on the relationship between stress at work, leisure time, and family). Unpublished doctoral dissertation. Berlin.

Blalock, H. M. (1961). Causal inferences in nonexperimental research. Chapel Hill: University of North Carolina Press.

Broadbent, D. E. (1982). Some relations between clinical and occupational psychology. Intemational Association of Applied Psychology: 20th International Congress. Edinburgh.

Campbell, D. T., \& Fiske, D. W. (1959). Convergent and discriminant validitation by the multitrait-multimethod matrix. Psychological Bulletin, 56, 81-105.

Caplan, R. D., Cobb, S., French, J. R. P., Jr., Harrison, R. V., \& Pinneau, S. R., Jr. (1975). Job demands and worker health. Washington: National Institute for Occupational Safety and Health, U.S. Department of Health, Education and Safety.

Cooper, C. L. (1981). The stress-check: Coping with the stress of life and work. Englewood Cliffs, NJ: Prentice Hall.

Cooper, C. L., \& Marshall, J. (1976). Occupational sources of stress: A review of the literature relating to coronary heart disease and mental ill health. Journal of Occupational Psychology, 49, 11-28.

Ellis, A. (1978). What people can do for themselves to cope with stress. In C. L. Cooper \& R. Payne (Eds.), Stress at work (pp. 209-222). Chichester: Wiley.

Fahrenberg, J. (1975). Die Freiburger Beschwerdeliste FBL (The Freiburg complaint list FBL). Zeitschrift fuer Klinische Psychologie, 4, 79-100.

Fein, M. (1976). Motivation for work. In R. Dubin (Ed.), Handbook of work, organization and society (pp. 465530). Chicago: Rand McNally.

Frese, M. (1978). Partialisierte Handlung und Kontrolle: Zwei Themen der industriellen Psychopathologie. In M. Frese, S. Greif, \& N. Semmer (Eds.) Industrielle Psychopathologie (pp. 159-183). Bern: Huber.

Frese, M. (1982). Occupational socialization and psychological development: An underemphasized research perspective in industrial psychology. Journal of Occupational Psychology, 55, 209-224.

Frese, M., \& Okonek, K. (1984). Night and shiftwork, psychological and psychosomatic complaints: Differentiations in the group of former shiftworkers. Journal of Applied Psychology, 68, 509-514.

Gardell, B. (1971). Technology, alienation and mental health in the modern industrial environment. In $\mathrm{L}$. Levi (Ed.), Society, stress and disease (Vol. 1; pp. 148180). London: Oxford University Press.

Gardell, B., \& Johansson, G. (Eds.) (1981). Working life: 
A social science contribution to work reform. Chichester: Wiley.

Greif, S., Bamberg, E., Dunckel, H., Frese, M., Mohr, G., Rueckert, D., Rummel, M., Semmer, N., \& Zapf, D. (1983). Abschlussbericht des Forschungsprojekts: "Psychischer Stress am Arbeitsplatzplatz-Hemmende und foerdernde Bedingungen fuer humanere Arbeitsplaetze" (Final report of the research project "Psychological stress at work-factors promoting and impeding humane working conditions). (Available from S. Greif, Fachbereich Psychologie, Universitaet Osnabrueck, Postfach 4469, 4500 Osnabrueck, Federal Republic of Germany).

Jones, E. E., Kanouse, D. E., Kelley, H. H., Nisbett, R. E. Valins, S., \& Weiner, B. (1972). Attribution: Perceiving the causes of behavior. Morristown, NJ: General Learning Press.

Kasl, S. V. (1978). Epidemiological contributions to the study of work stress. In C. L. Cooper \& R. Payne, (Eds.), Stress at work (pp. 3-48). Chichester: Wiley.

Karasek, R. A. (1979). Job demands, job decision latitude and mental strain: Implications for job design. Administrative Science Quarterly, 24, 285-308.

Karasek, R., Baker, D., Marxer, T., Ahlbohm, A., \& Theorell, T. (1981). Job decision latitude, job demands, and cardiovascular disease: A prospective study of Swedish men. American Journal of Public Health, 71, 694-705.

Kohn, M. L. (1973). Social class and schizophrenia: A critical review and a reformulation. Schizophenia Bulletin, No. 7, 60-79.

Kohn, M. L., \& Schooler, C. (1982). Job conditions and personality: A longitudinal assessment of their reciprocal effects. Journal of Sociology, 87, 1257-1286.

Kornhauser, A. (1965). Mental health of the industrial worker: A Detroit study. New York: Wiley.

Lazarus, R. S. (1966). Psychological stress and the coping process. New York: McGraw-Hill.

LaRue, A., Bank, L., Jarvik, L., \& Hetland, M. (1979). Health in old age: How do physicians' ratings and selfratings compare? Journal of Gerontology, 34, 687-691.

Maddox, G. L., \& Douglass, E. B. (1973). Self-assessment of health: A longitudinal study of elderly subjects. Journal of Health and Social Behavior, 14, 89-93.

Margolis, B. K., Kroes, W. H., \& Quinn, R. P. (1974). Job stress: An unlisted occupational hazard. Journal of Occupational Medicine, 16, 659-661.

McMichael, A. J. (1976). Standardized mortality ratios and the "healthy worker effect": Scratching beneath the surface. Journal of Occupational Medicine, 18, 165-168.

Meltzer, J. W., \& Hochstim, J. R. (1970). Reliability and validity of survey data on physical health. Public Health Report, 85, 1075-1086.

Mohr, G. (1985). Die Erfassung psychischer Befindensbeeintraechtigungen bei Industrie-Arbeitern (Measuring disturbance of psychological well-being in industrial blue-collar workers). Dissertation, Institut fuer Psychologie, Universitaet Osnabrück.

Mossey, J. M., \& Shapiro, E. (1982). Self-rated health:
A predictor of mortality among the elderly. American Journal of Public Health, 72, 800-808.

Orne, M. T. (1962). On the social psychology of the psychological experiment: With particular reference to demand characteristics and their implications. American Psychologist, 17, 776-783.

Pelz, D. C., \& Andrews, F. M. (1964). Detecting causal priorities in panel study data. American Sociological Review, 29, 836-848.

Rogosa, D. (1980). A critique of cross-lagged correlation. Psychological Bulletin, 88, 245-258.

Semmer, N. (1982). Stress at work, stress in private life and psychological well-being. In. W. Bachmann, I. Udris, \& J. Daniel (Eds.), Mental load and stress in activity: European approaches (pp. 42-52). Berlin (DDR): Deutscher Verlag der Wissenschaften, and Amsterdam \& New York: Elsevier-North Holland.

Semmer, N. (1984). Stressbezogene Taetigkeitsanalyse: Psychologische Untersuchungen zur Analyse von Stress am Arbeitplatz (Stress-oriented analysis of work: Psychological studies on the analysis of stress at work). Weinheim: Beltz.

Simon, H. A. (1954). Spurious correlation: A causal interpretation. Journal of the American Statistical Association, 49, 467-479.

Steiger, J. H. (1980). Tests for comparing elements of a correlation matrix. Psychological Bulletin, 87, 245251.

Waldron, I., Herold, J., \& Dunn, D. (1982). How valid are self-report measures for evaluating relationships between women's health and labor force participation? Women and Health, 7, 53-66.

Waldron, I., Herold, J., Dunn, D., \& Staum, R. (1982). Reciprocal effects of health and labor force participation among women: Evidence from two longitudinal studies. Journal of Occupational Medicine, 24, 126-132.

Wall, T. P., \& Clegg, C. W. (1981). A longitudinal study of group work design. Journal of Occupational Behavior, 2, 32-43.

Zaleznick, A., Ondrack, J., \& Silver, A. (1970). Social class, occupation and mental illness. In A. McLean (Ed.), Mental health and work organizations (pp. 116142). Chicago: Rand McNally.

Zapf, D., Bamberg, E., Dunckel, H., Frese, M., Greif, S., Mohr, G., Rueckert, D., \& Semmer, N. (1983). Dokumentation der Skalen des Forschungsprojekts "Psychischer Stress am Arbeitsplatz-Hemmende und fordernde Bedingungen fuer humanere Arbeitsplaetze" (Scale documentation of the research project "Psychological stress at work-factors promoting and impeding humane working conditions). (Available from D. Zapf, Institut fuer Psychologie, Freie Universitaet Berlin, Habelschwerdter Allee 45, 1000 Berlin 33, Federal Republic of Germany.)

Zedeck, S. (1971). Problems with the use of "moderator" variables. Psychological Bulletin, 76, 295-310.

Received February 10, 1984

Revision received September 17, 1984 